\title{
Backlash contra o sistema interamericano de direitos humanos. Uma análise sobre o caso Venezuela
}

\author{
Backlash against the Inter-American Human \\ Rights System. An Analysis of the Venezuela Case
}
Backlash contre le système interaméricain des droits de l'homme. Une analyse de l'affaire Venezuela

\section{Claudia Regina de Oliveira Magalhães da Silva Loureiro*}

\begin{abstract}
SUMÁRIO: I. Introdução. II. O caso Venezuela: contextualização fática. III. A Venezuela perante os sistemas internacionais de proteção aos direitos humanos. IV. A Opinião Consultiva solicitada pela Colômbia à Corte Interamericana de Direitos Humanos. V. Do regime jurídico interamericano aplicável ao caso. VI. Backlash Theory e os atos prarticados pela Venezue1a. VII. Argumentos que corroboram a ineficácia do backlash praticado pela Venezuela. VIII. Das consequências jurídicas dos atos de backlash praticados pela Venezuela. IX. Considerações finais. X. Referências bibliográficas.
\end{abstract}

* Universidade Federal de Uberlândia, Brasil; ORCID ID: https: / / orcid.org/0000-00020471-5711,crmloureiro@gmail.com. 
Resumo: O objetivo do artigo é analisar o movimento de ataque às instituições internacionais a partir do caso da Venezuela na visão da teoria denominada backlash e os prejuízos à cláusula democrática no sistema interamericano de direitos humanos. O trabalho abordará a situação da Venezuela perante o ordenamento jurídico doméstico e diante dos sistemas internacionais de proteção aos direitos humanos para contextualizar os efeitos do backlash no sistema interamericano, bem como as consequências da denúncia dos tratados internacionais e a retirada da Organização Internacional para a cláusula democrática e para a prevalência dos direitos humanos. O desenvolvimento do trabalho seguirá o método dedutivo, com a análise jurisprudencial e doutrinária relativa ao tema, no sentido de afirmar que não pode um Estado exonerar-se do dever de cumprir com os direitos humanos em razão da universalidade desses direitos, do direito transnacional e da globalização.

Palavras-chave: sistema interamericano de direitos humanos, backlash, denúncia a tratado internacional, retirada de organização internacional, ofensa à cláusula democrática.

ABSTRACT: The objective of the article is to analyze the movement of attack on international institutions from the case of Venezuela in the view of the theory called backlash and the damage to the democratic clause in the inter-american system of human rights. The work will address the situation of Venezuela before the domestic legal system and international systems of human rights protection to contextualize the effects of backlash in the inter-american system, as well as the consequences of the denunciation of international treaties and the withdrawal of the International Organization for the democratic clause and the prevalence of human rights. The development of the work will follow the deductive method, with jurisprudential and doctrinal analysis on the subject, to conclude that a State must observe human rights due to the universality of these rights, transnational law and globalization.

Key words: inter-american human rights system, backlash, denunciation of the international treaty, withdrawal of the international organization, offense to the democratic clause.

RÉSUMÉ: L'objectif de l'article est d'analyser le mouvement d'attaque contre les institutions internationales sur la base du cas du Venezuela à la lumière de la théorie appelée contrecoup et les dommages à la clause démocratique du système interaméricain des droits de l'homme. Les travaux porteront sur la situation du Venezuela devant le système juridique national et les systèmes internationaux de protection des droits de l'homme pour contextualiser les effets du contrecoup dans le Système Interaméricain, ainsi que les conséquences de la dénonciation des traités internationaux et du retrait de l'Organisation internationale pour la clause la démocratie et la prévalence des droits de l'homme. Le développement de l'ouvrage suivra la méthode déductive, avec l'analyse jurisprudentielle et doctrinale sur le sujet, dans le sens d'affirmer qu'un État ne peut pas s'exonérer du devoir de respecter les droits de l'homme en raison de l'universalité de ces droits, du droit transnational et de la mondialisation.

Mots-clés: système interaméricain des droits de l'homme, contrecoup, dénonciation d'un traité international, retrait d'une organisation internationale, infraction à la clause démocratique. 


\section{INTRODUÇÃO}

Os ataques às instituições internacionais motivaram a realização do estudo sobre a teoria denominada backlash e como ela influencia a estabilidade, a efetividade e a eficácia precisamente do sistema interamericano de proteção aos direitos humanos.

Recentemente, na América Latina, verifica-se uma corrente de quebra da cláusula democrática nos sistemas domésticos de alguns países, o que dá ensejo ao ataque às instituições interamericanas e internacionais, com a finalidade de enfraquecer o sistema e de rechaçar a proteção internacional dos direitos humanos para a perpetuação do poder autoritário.

O trabalho seguirá o método dedutivo, com a revisão bibliográfica e jurisprudencial para defender a ideia de que os ataques às instituições democráticas internacionais refletem a prática do backlash.

Inicialmente, o artigo fará a narrativa dos fatos envolvendo a Venezuela para efeito de contextualização da teoria mencionada, a fim de demonstrar que a postura daquele País tem a finalidade de enfraquecer a legitimidade do sistema interamericano de proteção aos direitos humanos com a severa contestação de sua autoridade e capacidade, o que pode ser confirmado a partir da constatação da situação da Venezuela perante os Sistemas Internacionais de Proteção aos Direitos Humanos, bem como perante o Tribunal Penal Internacional.

$\mathrm{Na}$ sequência, o trabalho analisará a relação que existe entre a Opinião Consultiva solicitada pela Colômbia à Corte Interamericana de Direitos Humanos com a postura da Venezuela de se retirar da OEA e de denunciar a Convenção Americana de Direitos Humanos e abordará quais são as consequências jurídicas dos atos de backlash praticados pela Venezuela.

Além disso, o trabalho afirmará que existem determinadas obrigações que são inderrogáveis para os Estados por decorrerem do contexto das normas de natureza jus cogens, do direito costumeiro e da transnacionalidade das relações travadas no âmbito da globalização.

O trabalho concluirá que, em que pese o Estado tenha o direito de se retirar de uma organização internacional e de denunciar um tratado internacional, seus atos unilaterais nem sempre alcançarão o efeito de exonerá-lo do cumprimento de suas obrigações em relação aos direitos humanos, se 
forem praticados em desrespeito às instituições democráticas domésticas e em razão de sua universalidade.

\author{
II. O CASO VENEZUELA: \\ CONTEXTUALIZAÇÃO FÁTICA
}

Desde de abril de 2017, a Venezuela tem presenciado protestos contra o regime do presidente Nicolas Maduro, denominado de "Plano Zamorra", após a Suprema Corte assumir os poderes da Assembleia Geral e limitar as imunidades parlamentares, o que a oposição denominou de golpe, uma vez que o governo reorganizou a divisão dos poderes e deflagrou novas eleições.

Em 1.04.2017, o presidente Nicolas Maduro anunciou que iniciaria o processo para retirar a Venezuela da Organização dos Estados Americanos, depois que membros da Organização se reunirem para discutir a situação da Venezuela. Em 1.05.2017, após o anúncio do Presidente Maduro de que instituiria uma nova Assembleia Nacional Constituinte, para elaborar uma nova Constituição, houve uma sequência de protestos seguidos do anúncio de participação das forças oficiais da polícia e militares, bem como de grupos civis armados para conter as manifestações.

A eleição para a ANC foi realizada em 30.07.2017 e o presidente Maduro obteve as 545 cadeiras na nova Assembleia, o que foi criticado pela oposição, por outros países e por organizações internacionais, pela conotação fraudulenta. Fontes anunciaram que as forças de segurança dos Estados atuaram com força excessiva para controlar os protestos, o que resultou em mortes e pessoas feridas entre abril e julho de 2017. Além disso, protestantes foram levados às cortes militares e as pessoas presas foram vítimas de abuso e de tratamento desumano.

Em 20.05.2018, novas eleições foram realizadas e Maduro foi reeleito para mais um mandato de 6 anos, resultado que foi contestado sob alegação de fraude e de irregularidades. O Grupo Lima, composto por 14 Estados Latino-Americanos e pelo Canadá, decidiu não reconhecer a legitimidade do governo Maduro sob a alegação de que o governo não respeitou os standards internacionais para um processo democrático, justo, livre e transparente. 
Esta revista forma parte del acervo de la Biblioteca Jurídica Virtual del Instituto de Investigaciones Jurídicas de la UNAM

A crise econômica, política e financeira da Venezuela tem causado a migração involuntária dos venezuelanos, sendo que mais de 3,4 milhões de nacionais daquele país migraram para outros países próximos, especialmente Brasil e Colômbia, devido ao receio de ficar sem comida, sem remédio e sem acesso aos serviços sociais básicos de seu país. ${ }^{1}$

A situação é tão grave que chamou a atenção dos Sistemas internacionais de proteção aos direitos humanos, conforme será analisado a seguir.

\section{A VENEZUELA PERANTE OS SISTEMAS INTERNACIONAIS DE PROTEÇÃO AOS DIREITOS HUMANOS}

A situação de degradação dos direitos humanos na Venezuela despertou a preocupação do Alto Comissariado das Nações Unidas sobre Direitos Humanos, que publicou Resolução ressaltando as violações aos direitos humanos e abusos cometidos nos protestos que ocorreram na Venezuela de 01.04 a $31.07 .2017 .^{2}$

1 Sobre a situação da Venezuela, consultar: Dooy, Shannon et al., "Venezuelan Migration and the Border Healthy Crisis in Colombia and Brazil”, Journal on Migration and Human Security, Baltimore, núm. 3, 2019. Disponível em: https://journals.sagepub.com/ doi/pdf/10.1177/2331502419860138; United Nations High Commissioner for Human Rights, "Venezuela Situation. Responding to the Needs of People Displaced from Venezuela, Supplementary Appeal”, 2018. Disponível em: https://www.unhcr.org/partners/ donors / 5 ab8e1 a 17 / unhcr-2018-venezuela-situation-supplementary-appeal-january-december-2018.html; Bahar, Dany et al., "Integrating Venezuelans into the Colombian Labor Market. Mitigating Costs and Maximizing Benefitis", Global Economy and Development at Brookings, 2018. Disponível em: https://www.brookings.edu/wp-content/uploads/2018/12/ Venezuelan-Migrants_English.pdf; Ramsey, Geoff e Sanchez-Grazoli, Gimena, "Responding to an Exodus, Venezuela's Migration and Refugees Crisis as Seen from the Colombian and Brazilian Borders", WOLA, Advocacy for Human Rights in the Americas, Research Report, jul. de 2018. Disponível em: https://www.wola.org/wp-content/uploads/2018/07/Final-VZ-Mi gration-Report-Final.pdf; Human Rights Watch, "The Venezuelan Exodus, the Need for International Protection and the Region's Response”, 2018. Disponível em: https: / / www.hrw. org/pt/report/2018/09/03/322156.

2 Cfr., Resolução do Alto Comissariado das Nações Unidas sobre Direitos Humanos. Disponível em: https: / / nacoesunidas.org/conselho-de-direitos-humanos-pede-que-venezuela-aceite-assis tencia-humanitaria/. 
O Conselho de Direitos Humanos da Organização das Nações Unidas aprovou em 27.09.2019, em Genebra, uma Resolução para criar um órgão independente para investigar os crimes cometidos na Venezuela desde 2014, com o objetivo de documentar abusos e violações visando a responsabilização internacional do Estado. ${ }^{3}$ Consta que a missão trabalhará em cooperação com o Tribunal Penal Internacional para compartilhamento de provas, informações e documentos, uma vez que o caso já está em Investigação Preliminar perante o Tribunal Penal Internacional, desde fevereiro de $2018 .{ }^{4}$

Por sua vez, a CIDH (Comissão Interamericana de Direitos Humanos), órgão autônomo e independente, pertencente ao sistema interamericano, elaborou o relatório sobre a situação dos direitos humanos na Venezuela, que foi aprovado em 31.12.2017, o que foi motivado pela grave deterioração dos direitos humanos no país e pela grave crise política, econômica e social que se intensificou em 2017, com a indevida ingerência do Poder Executivo nos demais poderes, com impacto no princípio da separação dos poderes. ${ }^{5}$

Ao elaborar o relatório, a CIDH analisou detalhadamente a situação dos direitos humanos no país frente ao Sistema interamericano de proteção aos direitos humanos. ${ }^{6}$ Concretamente, a CIDH centrou a sua análise nas obrigações contidas na Declaração Americana de Direitos e Deveres do Homem de 1948 e na Carta da OEA do mesmo ano, bem como em outros tratados interamericanos, o que resultou na elaboração de algumas recomendações. ${ }^{7}$

3 "O Conselho de Direitos Humanos adotou esta sexta-feira, em Genebra, uma resolução para criar um órgão independente para investigar crimes cometidos na Venezuela desde 2014. A Resolução foi apresentada pelo Grupo de Lima, formado por 10 países, incluindo Brasil e Canadá. Foi aprovada com 19 votos a favor e sete contra”. Resolução do Conselho de Direitos Humanos da ONU. Disponível em: https://news.un.org/pt/story/2019/09/1688872.

4 International Criminal Court, "Report on Preliminar Examination Activities", Haia, 2018, p. 43. Disponível em: https: / / www.icc-cpi.int/itemsDocuments/181205-rep-otp-PE-ENG.pdf.

5 Comissão Interamericana de Direitos Humanos, "Relatório da Venezuela de 2017", Washington DC, 2017. Disponível em: http://www.oas.org/es/cidh/informes/pdfs/Venezuela2018-es.pdf.

6 Ibidem, pp. 29-44.

7 Ibidem, p. 43: "A Comissão Interamericana de Direitos Humanos concluiu o seu relatório com as seguintes Recomendações à Venezuela: a) o dever de o País ratificar a Convenção Americana de Direitos Humanos de 1969 e de reconhecer da competência da Corte 
Esta revista forma parte del acervo de la Biblioteca Jurídica Virtual del Instituto de Investigaciones Jurídicas de la UNAM

Por outro lado, a situação de degradação dos direitos humanos na Venezuela chamou a atenção e despertou a preocupação do Alto Comissariado das Nações Unidas sobre Direitos Humanos, que publicou uma Resolução ${ }^{8}$ ressaltando as violações aos direitos humanos e abusos cometidos nos protestos que ocorreram na Venezuela de 1.04 a 31.07.2017. Além disso, o Conselho Permanente da OEA concordou em não reconhecer a legitimidade do governo no período de Nicolas Maduro a partir de 10.01.2019.9

A Comissão Interamericana de Direitos Humanos elaborou, ainda, a Resolução $n^{\circ}$ 2/2018 sobre a situação da Venezuela, onde ressalta a grave e generalizada ausência de proteção do Estado e a violação dos direitos fundamentais dos cidadãos venezuelanos. ${ }^{10}$

Além disso, a situação da Venezuela já é objeto de análise pelo Tribunal Penal Internacional, como se pode verificar do Relatório de Atividades de Exames Preliminares, em exame desde fevereiro de 2018, após o Gabinete da Procuradora ter recebido 110 comunicações que pleiteiam a aplicação do artigo 15 do Estatuto de Roma de 1998 em relação aos eventos que vem ocorrendo desde abril de 2017 na Venezuela. ${ }^{11}$ É preciso ressaltar que o Tribunal Penal Internacional tem jurisdição sobre o caso uma vez que a Venezuela depositou seu instrumento de ratificação ao Estatuto de Roma em 7.6.2000.

Interamericana de Direitos Humanos; b) a necessidade de a Venezuela reverter a decisão de se retirar da OEA; c) o dever de a Venezuela tornar sem efeito as medidas que impedem as pessoas de deixarem o território venezuelano e de solicitar asilo ou outra forma de proteção em outro Estado”.

8 Resolução do Alto Comissariado das Nações Unidas sobre Direitos Humanos, op. cit.

9 Cfr. Organização dos Estados Americanos, Resolução núm. 2929/2018, Washington DC, 2018, https: / / www.oas.org/pt/centro_midia/nota_imprensa.asp?sCodigo=P-001/19; Comissão Interamericana de Direitos Humanos, op. cit., p. 43.

10 Cfr. Organização dos Estados Americanos, Resolução núm. 2/2018, Washington DC, 2018. Disponível em: https://www.oas.org/pt/cidh/decisiones/pdf/Resolucao-2-18-pt.pdf.

11 Cfr. International Criminal Court, op. cit., p. 29: "Em 27/09/2019, o Gabinete da Procuradora recebeu uma remessa de um grupo de Estados-Partes do Estatuto (Argentina, Canadá, Colômbia, Chile, Paraguai e Peru) a respeito da situação da Venezuela, com base no artigo 14 do Estatuto de Roma de 1998, requerendo que a Procuradoria inicie uma investigação sobre a alegação de crimes contra a humanidade cometidos no território da Venezuela desde 12/02/2014, utilizando-se do Relatório da Organização dos Estados Americanos sobre a Venezuela como fonte. Em 28/09/2018, a Presidência do Tribunal encaminhou a situação da Venezuela para a Câmara de Pré-julgamento I.” 
Esta revista forma parte del acervo de la Biblioteca Jurídica Virtual del Instituto de Investigaciones Jurídicas de la UNAM

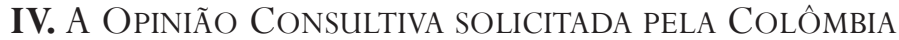 À CORTE INTERAMERICANA DE DiREITOS Humanos}

A República da Colômbia solicitou, em abril de 2019, Opinião Consultiva ${ }^{12}$ à Corte Interamericana de Direitos Humanos, com fulcro no artigo 64.1 do Pacto de San José da Costa Rica, ${ }^{13}$ uma vez que é Estado-membro da OEA e Estado-parte da Convenção Americana de Direitos Humanos, bem como em conformidade com as estipulações dos parágrafos $1^{\circ}$ e $2^{\circ}$ do artigo 70 do Regulamento da Corte. ${ }^{14}$

A consulta se refere às obrigações em matéria de direitos humanos e aos mecanismos de proteção internacional dos direitos humanos existentes nos países que pretendem abandonar o sistema interamericano de direitos humanos ao denunciar a Convenção Americana de Direitos Humanos e a Carta da Organização dos Estados Americanos com a tentativa de deixar de ser membros da organização internacional regional. ${ }^{15}$

A Declaração Americana é o texto que determina quais são os direitos humanos a que se referem a Carta da OEA para os Estados membros da Organização, além de constituir fonte das obrigações internacionais para

12 Cfr. Corte Interamericana de Direitos Humanos, "Parecer Consultivo solicitado pela Colômbia em abril de 2019”, Costa Rica, 2019. Disponível em: http://www.corteidh.or.cr/ docs/opiniones/sol_oc_26_por.pdf.

13 Cfr. Artigo 64.1 do Pacto de São José da Costa Rica, 1969: “Os Estados membros da Organização poderão consultar a Corte sobre a interpretação desta Convenção ou de outros tratados concernentes à proteção dos direitos humanos nos Estados Americanos”.

14 Cfr. Corte Interamericana de Direitos Humanos, OC-1/82, Costa Rica, 1982, parágrafo 34. Disponível em: http://www.corteidh.or.cr/docs/opiniones/seriea_01_esp1.pdf; e OC-10/89, parágrafo 44. Disponível em: http://www.corteidh.or.cr/docs/opiniones/seriea_10_esp1.pdf. O artigo 64 da Convenção Americana de Direitos Humanos estabelece a competência da Corte para emitir Opiniões Consultivas. Além disso, a competência ratione personae da Corte também se aplica pelo fato de a República da Colômbia, Estado solicitante, ser Estado membro da OEA. A Corte também tem competência ratione loci, pois a consulta se refere claramente à proteção dos direitos humanos em qualquer Estado americano. Por sua vez, a competência ratione materiae também está preenchida, uma vez que a consulta se refere à interpretação da Convenção e de "outros tratados concernentes à proteção dos direitos humanos nos Estados americanos", em particular a Carta da OEA e a Declaração Americana dos Direitos e Deveres do Homem de 1948.

15 Cfr. Corte Interamericana de Direitos Humanos, "Parecer Consultivo...", cit. 
Esta revista forma parte del acervo de la Biblioteca Jurídica Virtual del Instituto de Investigaciones Jurídicas de la UNAM

estes. Por outro lado, a Convenção Americana é a fonte das obrigações para os Estados partes que não se liberam das obrigações da Declaração por serem membros da OEA. ${ }^{16}$

A jurisprudência da Corte Interamericana de Direitos Humanos estabelece que a competência consultiva da Corte constitui um método judicial alternativo para a proteção dos direitos humanos internacionalmente reconhecidos, de modo que referida competência não pode resultar numa especulação puramente acadêmica sem a previsibilidade de aplicação a situações concretas que justifiquem o interesse na emissão do parecer. ${ }^{17}$

Desse modo, a situação concreta que justifica a emissão do Parecer Consultivo pela Corte Interamericana de Direitos Humanos é o movimento de países latino-americanos no sentido de se desligarem do sistema interamericano, com a denúncia da $\mathrm{CADH}$, bem como da Carta da OEA, o que decorre da prática denominada backlash, conforme será demonstrado no artigo. ${ }^{18}$

O enfraquecimento da eficácia e da efetividade dos documentos interamericanos ora apontados fortalece os movimentos de contestação e de negação da legitimidade e da autoridade das instituições interamericanas. Por isso, oportuno estudar o regime jurídico interamericano aplicável ao backlash em estudo.

16 Cfr. Corte Interamericana de Direitos Humanos, OC-16/99, Costa Rica, 1999, parágrafo 47. Disponível em: https://www.corteidh.or.cr/docs/opiniones/seriea_16_esp.pdf; OC18/03, Costa Rica, 2003, parágrafo 63. Disponível em: https://www.corteidh.or.cr/docs/opi niones/seriea_18_esp.pdf. Além de ter competência para emitir pareceres consultivos, a Corte também tem competência para avaliar, em cada pedido concreto, a pertinência de exercer a sua função consultiva, o que tem relação com o princípio da "competência da competência", que não pode ser discricionário, pois, para abster-se de responder a uma consulta, a Corte necessita fundamentar sua decisão, por exemplo, pela falta de cumprimento dos requisitos da petição, exigidos pela Convenção Americana, conforme dispõe o artigo 66 da Convenção. Ademais, a solicitação de Parecer Consultivo não pode ser usada para obter um pronunciamento prematuro da Corte sobre caso futuro, para obter um pronunciamento indireto sobre um caso em litígio, para debate político, para pronunciamento de temas sobre os quais a Corte já se pronunciou ou para solucionar questões de fato.

17 Cfr. Corte Interamericana de Direitos Humanos, OC-9/87, Costa Rica, 1987, parágrafo 16. Disponível em: http://www.corteidh.or.cr/docs/opiniones/seriea_09_esp.pdf.

18 Soley, Ximena e Steininger, Silvia, "Parting Ways or Lashing back? Withdrawals, Backlash and the Inter-American Court of Human Rights", International Journal of Law in Context, Cambridge, maio de 2018, pp. 237-257. Disponível em: https: //doi.org/10.1017/S174 4552318000058 . 


\section{DO REGIME JURÍDICO INTERAMERICANO \\ APLICÁVEL AO CASO}

A Declaração Americana de Direitos e Deveres do Homem de 1948 é o documento que rege as obrigações dos Estados pertencentes à Organização dos Estados Americanos e que estabelece seus direitos e deveres, ou seja, suas obrigações. ${ }^{19}$

O preâmbulo da Declaração preconiza o sentimento de que a finalidade principal de todas as instituições políticas e jurídicas é a proteção dos direitos essenciais do homem e a criação de circunstâncias que permitam alcançar a felicidade e que os direitos essenciais do homem não decorrem do vínculo jurídico-político que o ser humano tem com determinado Estado, mas sim de sua condição humana.

Além disso, a Resolução concilia a consagração americana dos direitos do homem com as garantias oferecidas pelos regimes domésticos como um sistema inicial de proteção aos direitos humanos, ressaltando, em seu preâmbulo, a liberdade e igualdade em direitos e dignidade de todos os seres humanos, bem como a fraternidade.

A Corte Interamericana de Direitos Humanos entende que os direitos fundamentais garantidos na Carta da OEA são todos aqueles previstos na Declaração Americana dos Direitos e Deveres do Homem de 1948, que estabelece direitos e deveres para todos os Estados-membros da OEA, principalmente o dever de respeitar os direitos humanos dos seus cidadãos garantidos pela Declaração Americana. ${ }^{20}$

O artigo 1o. da Declaração Americana de Direitos e Deveres do Homem de 1948 protege o direito à vida e a Comissão Interamericana tem aplicado o conceito de jus cogens para abranger determinados direitos previstos na Declaração, que é considerada soft law. Assim, a Comissão Interamericana pode emitir Recomendações em relação a determinado

19 Cfr., Declaração Americana de Direitos e Deveres do Homem, 1948. Disponível em: https: / / www.cidh.oas.org/basicos/portugues/b.Declaracao_Americana.htm.

20 Cfr. Concepcion, Natasha, “The Legal Implications of Trinidad \& Tobago's Withdrawal from the American Convention on Human Rights", American University International Law Review, Washington DC, núm. 3, 2001, pp. 847-890. Disponível em: https: / digitalcommons.wcl. american.edu/cgi / viewcontent.cgi?article $=1242$ \&context $=$ auilr. 
Estado e, ao constatar que um Estado violou a Declaração, deve iniciar o monitoramento.

A propósito, o artigo 1 (2) (b) do Estatuto da CIDH estabelece que o órgão tem a autoridade para administrar a Declaração Americana em relação aos Estados-membros não pertencentes à Convenção Americana, inclusive em relação aqueles que a denunciaram, caso em que os Estados continuam obrigados a certos direitos decorrentes da Declaração Americana. ${ }^{21}$

Assim, se um Estado denuncia a Convenção Americana, os direitos humanos dos cidadãos continuam protegidos pela Declaração Americana. Entretanto, necessário se faz questionar o que ocorre com os direitos humanos e com a aplicação dos standards decorrentes da Declaração Americana quando o Estado denuncia a Carta da OEA, o que será debatido em capítulo apropriado.

Outro documento interamericano a ser interpretado pela Corte no Parecer Consultivo, que compõe o regime jurídico decorrente do sistema interamericano, é a Carta da Organização dos Estados Americanos, documento que tem como objetivo fornecer ao homem uma América, terra de liberdades e ambiente favorável ao desenvolvimento de sua personalidade para o convívio em paz e com respeito à soberania, independência, igualdade e direito, com base na solidariedade americana e respeito aos direitos essenciais do homem. ${ }^{22}$

A Carta da OEA também preconiza a cooperação internacional e o bem-estar de todos, bem como a ideia de que os direitos fundamentais da pessoa humana independem de raça, nacionalidade, credo ou sexo, em decorrência do princípio da igualdade. O documento ainda prevê a liberdade dos Estados para o exercício de sua soberania, desde que com respeito aos direitos da pessoa humana e aos princípios da moral universal.

Por sua vez, a Convenção Americana de Direitos Humanos de 1969 é o documento interamericano que tem como fundamento os princípios da democracia, da liberdade pessoal, da justiça social, do respeito aos direitos essenciais do homem e da proteção internacional. ${ }^{23}$ A Convenção ainda tem fundamento no valor de que o ser humano só realiza o seu ideal se estiver

${ }^{21}$ Cfr. Estatuto da Comissão Interamericana de Direitos Humanos. Disponível em: https: / / www.cidh.oas.org/basicos/portugues/t. Estatuto.CIDH.htm.

22 Cfr. Carta da Organização dos Estados Americanos. Disponível em: https://www.oas. org/dil/port/tratados_A-41_Carta_da_Organização_dos_Estados_Americanos.pdf.

${ }^{23}$ Cfr. Convenção Americana de Direitos Humanos, 1969. Disponível em: https://www. cidh.oas.org/basicos/portugues/c.convencao_americana.htm. 
livre da miséria e do temor, realidade que só se alcança com a prevalência dos direitos econômicos, sociais, culturais, civis e políticos.

Além disso, a Convenção em apreço deve ser interpretada de modo a não suprimir o gozo e o exercício dos direitos e liberdades por ela reconhecidos, nem os direitos e garantias inerentes ao ser humano ou que decorram da forma democrática e representativa do governo.

O artigo 78 da Convenção Americana estabelece o direito de o Estado denunciar a Convenção, o que, no entanto, não atinge atos pretéritos ao ato unilateral. Entretanto, referida denúncia deve ser feita em atenção em consonância com os standards interpretativos da Convenção e dos demais documentos interamericanos, conforme será detalhado oportunamente. ${ }^{24}$

A prática do backlash visa enfraquecer a legitimidade do regime jurídico decorrente do sistema interamericano com o intuito de fomentar o raciocínio de que só se aplicam aos Estados as regras decorrentes da manifestação de sua vontade como decorrência de sua soberania estatal, o que não se aplica em relação aos comportamentos que estão dentro do contexto dos interesses da humanidade, o que será explicado a seguir.

\section{BACKLASH THEORY E OS ATOS PRATICADOS PELA VENEZUELA}

O contexto fático da Venezuela demonstra que a democracia global tem sido desafiada pela resistência dos Estados em relação às normas, procedimentos e instituições de governança global, com a ameaça dos Estados de retirada das organizações internacionais ou de denúncia dos tratados internacionais, com o non-compliance, com o desrespeito às obrigações internacionais e com a recusa em implementar os julgamentos dos sistemas regionais de direitos humanos, fenômeno que vem sendo denominado de backlash pelos doutrinadores, o que atinge os sistemas regionais de proteção aos direitos humanos e os ideais de justiça global. ${ }^{25}$

Referida postura atinge não só os sistemas internacionais de proteção aos direitos humanos, bem como os ideais de justiça global incorporados pelos

24 Cfr. Artigo 78 da Convenção Americana de Direitos Humano, 1969. Disponível em: https: / / www.cidh.oas.org/basicos/portugues/c.convencao_americana.htm.

25 Soley, Ximena e Steininger, Silvia, op. cit., pp. 1 e 2. 
sistemas internacionais, especialmente pela Corte Interamericana de Direitos Humanos como uma forte resistência ou reação contra a efetividade do Sistema Interamericano de Direitos Humanos. ${ }^{26}$

O Dicionário Merrien Webster define backlash como "a sudden violent backward movement or reaction" e como "a strong adverse reaction (as to a recent political or social development)". No mesmo sentido, Jane Manbridge e Shauna Shames definem backlash como "the use of coercive power to regain lost power as capacity". ${ }^{27}$ Dessa forma, pode-se afirmar que backlash refere-se a um processo de resistência dinâmico que vai desde a objeção, passa pela contestação, pela resistência, até desembocar num forte movimento que vai além das reações ordinárias anteriormente citadas.

Pode um Estado, portanto, praticar o backlash contra uma instituição internacional, em especial contra um tribunal internacional ao questionar sua efetividade, ao não adaptar seu ordenamento doméstico à instituição, ao não observar um julgamento, ou ao contestar sua autoridade. ${ }^{28}$

No entanto, a prática do backlash não se caracteriza apenas por uma contestação ou reação, que são práticas ordinárias de crítica a um julgamento ou a uma norma em particular, mas sim através de uma resistência sistemática e intensa contra a autoridade de uma instituição internacional ou tribunal internacional. São atos que vão além da resistência e visam reduzir a autoridade, a competência e a jurisdição da Corte. ${ }^{29}$

Um Estado autoritário só respeitará um sistema internacional de proteção aos direitos humanos se o custo de sua permanência no sistema não atingir sua soberania, não atacar o seu regime e não dificultar sua adapta-

26 A suprema Corte da Argentina entendeu que a Corte IDH agiu ultra vires ao tornar um julgamento local sem efeito. Cfr. Corte Interamericana de Direitos Humanos, caso Fontevecchia \& D'Amico vs. Argentina, Costa Rica, 2011. Disponível em: http: / /www.corteidh.or.cr/docs/ casos/articulos/seriec_238_por.pdf.

27 Soley, Ximena e Steininger, Silvia, op. cit., p. 4.

28 Ainda a propósito da teoria do backlash, cfr.: Alter, Karen J. and Zurn, Michael, "Backlash Politics: Introduction to a Symposium on Backlash Politics in Comparison, Forthcoming in the British Journal of Politics and International Relations, as Part of a Special Issue on Backlash Politics in Comparison”, iCourts Working Paper Series, Copenhagen, núm. 174, novembro de 2019, https://papers.ssrn.com/sol3/papers.cfm?abstract_id=3481735; Ehrhardt, Matthias, "Why Parties Politicize International Institutions: On Globalization Backlash and Authority Contestation”, Review International Political Economy, Londres, núm. 6, 2014. Disponível em: https: / / www.tandfonline.com/doi / full/10.1080/09692290.2013.839463.

29 Soley, Ximena e Steininger, Silvia, op. cit., p. 6. 
ção, caso contrário, o estado iniciará a prática do backlash, como forma de retirar a legitimidade de uma instituição ou de um tribunal internacional, a exemplo da Rússia em relação à União Europeia, dos EUA em relação ao Tribunal Penal Internacional, no caso Afeganistão, e do Brasil em face da Corte Interamericana em relação ao caso Gomes Lund.

Assim, a Venezuela inicia a prática do backlash quando noticia a sua retirada do sistema interamericano em 28.04.2017 e quando denuncia a Convenção Americana de Direitos Humanos em 10.09.2013, uma vez que a sua permanência no sistema passou a gerar um custo além de suas expectativas, de forma a impedir que o regime autoritário se perpetuasse no poder.

Situação semelhante foi a de Trinidad \& Tobago, do Perú, e da República Dominicana, mas cada qual com intensidades e propósitos diferenciados. No caso de Trinidad \& Tobago, não se pode afirmar que houve a prática do backlash, uma vez que a contestação se dirigiu à aplicação de uma norma específica e não à existência da instituição. Em se tratando do Perú, pode-se afirmar que houve a prática de resistência contra a Corte Interamericana de Direitos Humanos, com a denúncia da Convenção Americana de Direitos Humanos de 1969, em razão de mudanças na política doméstica do país, na era Fujimori. Quanto à República Dominicana, é possível afirmar que ocorreu efetivamente o backlash, uma vez que a resistência ao caso da expulsão dos haitianos não ficou restrita apenas ao julgamento, mas atingiu a estrutura e a autoridade da Corte. ${ }^{30}$

Assim, importante esclarecer que o backlash diferencia-se da mera contestação por parte dos Estados a determinadas normas ou ao cumprimento de determinados julgamentos, mas avança para alcançar a autoridade das instituições internacionais, com a finalidade de atingir e reduzir a sua legitimidade, enfraquecendo, consequentemente, a concretização dos direitos humanos em determinado sistema. ${ }^{31}$

30 Cfr. Corte Interamericana de Direitos Humanos, caso Hilaire e outros vs. Trinidad \&Tobago, Costa Rica, 2002. Disponível em: http://www.corteidh.or.cr/docs/casos/articulos/Seriec_94_ esp.pdf; caso Barrios Altos vs. Peru, Costa Rica, 2001. Disponível em: https://www.cnj.jus.br/wp -content/uploads /2016/04/092b2fec1 ad5039b26ab5f98c3f92118.pdf; caso Pessoas Expulsadas vs. República Dominicana, Costa Rica, 2014. Disponível em: http: / / www.corteidh.or.cr/docs/casos / articulos/seriec_282_esp.pdf.

31 A propósito da ideia, $c f r$. Burchardt, Dana, “'Backlash against the Court of Justice of the EU? The Recent Jurisprudence of the German Constitutional Court on EU Fundamental Rights as a Standard", Review German Law Journal, Cambridge, núm. 21, março de 2020, pp. 
Foi exatamente o que ocorreu no caso Venezuela, em que a retirada do sistema interamericano e a denúncia à Convenção decorreram de uma postura sistemática e contumaz do Estado no sentido de atacar a autoridade do sistema para vingar o seu estado autoritário, exonerando-se da responsabilidade de proteger, observar e concretizar os direitos humanos naquele país.

Por isso, a prática do backlash pela Venezuela contra o sistema interamericano não é somente uma consequência da implantação do regime autoritário no país, mas também configura um ataque ao sistema interamericano de direitos humanos, que se viu desafiado para manter sua efetividade e autoridade perante os demais países da América Latina ainda tão frágeis na consolidação do Estado Democrático de Direito.

Logo, o backlash da Venezuela não pode ser tolerado pelo sistema interamericano de proteção aos direitos humanos sob pena de se criar um efeito dominó que se expandirá para outras democracias forjadas, conforme anunciado por José Saramago. ${ }^{32}$

Logo, os atos praticados pela Venezuela não acarretam a consequência desejada de exonerar o Estado do cumprimento das obrigações decorrentes dos direitos humanos, devido à implicação das normas jus cogens e do direito costumeiro, além da possibilidade de aplicação da tese do direito transnacional, do direito cosmopolita e do princípio da cooperação, conforme será analisado a seguir.

\section{ARGUMENTOS QUE CORROBORAM A INEFICÁCIA DO BACKLASH PRATICADO PELA VENEZUELA}

Um dos argumentos mais relevantes para corroborar a afirmação de que a Venezuela pratica backlash e que tais atos não surtem efeitos em relação aos direitos humanos é a norma de natureza jus cogens.

1-18. Disponível em: https://doi.org/10.1017/glj.2020.16. "The second criterion for categorizing the decisions on the Right to be forgotten as backlash or resistance against the CJEU is that these decisions represent an action that aims «o reduce the authority, competence, or jurisdiction» of the CJEU”.

32 Saramago, José, Ensaio sobre a lucidez, São Paulo, Companhia das Letras, 2004. 
Esta revista forma parte del acervo de la Biblioteca Jurídica Virtual del Instituto de Investigaciones Jurídicas de la UNAM

As normas de natureza jus cogens ${ }^{33}$ representam o new jus gentium do direito internacional da humanidade e se estendem para todo o corpus juris do direito internacional contemporâneo, projetando-se, para o direito doméstico e invalidando qualquer medida ou ato incompatível com ela. São normas que, pela sua natureza inderrogável, têm incidência sobre as fundações de um direito internacional universal, sendo a base do novo jus gentium. ${ }^{34}$

Para a proteção dos seres humanos, as normas jus cogens integram o universo conceitual do direito internacional contemporâneo e consagram a visão universalista de que as normas cogentes não derivam da vontade dos Estados, mas sim da consciência humana, ou seja, da opinio juris communis de todos os sujeitos de direito internacional, estados, organizações internacionais, seres humanos e a humanidade como um todo, o que reflete a humanização do direito internacional. ${ }^{35}$

As normas de natureza jus cogens atendem à necessidade mínima de verticalização da ordem jurídica internacional, em especial da soberania estatal para efeito de se alcançar a proteção e a concretização dos direitos huma-

33 Cfr. Corte Interamericana de Direitos Humanos, OC-18/03, Costa Rica, 2003, parágrafos 97-100, pp. 116-117. Disponível em: http://www.corteidh.or.cr/docs/opiniones/ seriea_18_esp.pdf: Os tribunais internacionais vêm contribuindo consideravelmente para a construção do jus cogens, podendo-se citar, por exemplo, o Tribunal Penal Internacional para a ex-Iugoslávia como o tribunal que mais contribuiu para a evolução conceitual das normas jus cogens. Ademais, a Corte Interamericana de Direitos Humanos tem contribuído para a expansão do conceito material de jus cogens, com o entendimento da absoluta proibição de tortura e de tratamento desumano, cruel e degradante, seguida do princípio da igualdade e da não-discriminação.

34 Cfr. Cançado Trindade, Antonio Augusto, $O$ direito internacional em um mundo em transformação, Rio de Janeiro, Renovar, 2002, p. 1077. “Um novo cenário internacional passou a desvendar-se, em que não mais se sustentava o monopólio estatal da titularidade de direitos, e em que se figurava esgotado e superado o modelo Westphaliano do ordenamento internacional. De certo modo, a própria dinâmica da vida internacional cuidou de desautorizar o entendimento tradicional de que as relações internacionais se regiam por regras derivadas única e inteiramente da livre vontade dos próprios Estados. O positivismo voluntarista mostrou-se incapaz de explicar o processo de formação das normas de Direito Internacional geral, e se tornou evidente que só poderia encontrar uma resposta ao problema dos fundamentos e da validade deste último na consciência jurídica universal, a partir da asserção da ideia de uma justiça objetiva. O ordenamento internacional das soberanias cedeu efetivamente terreno ao da solidariedade".

35 Cfr. Cançado Trindade, Antonio Augusto, "Jus Cogens: The Determination and the Gradual Expansion of its Material Content in contemporary International Case-Law", s/f. Disponível em: https: / /www.oas.org/dil/esp/3\%20-\%20cancado.LR.CV.3-30.pdf. 
Esta revista forma parte del acervo de la Biblioteca Jurídica Virtual del Instituto de Investigaciones Jurídicas de la UNAM

nos. Referida verticalização se dá no sentido de transcendência do direito dos tratados e das regras de responsabilização dos Estados, alcançando o direito internacional geral e os fundamentos da ordem jurídica internacional, o que ficou ressaltado no artigo 53 da Convenção de Viena sobre o Direito dos Tratados de 1969, na Opinião Consultiva da Corte Internacional de Justiça de 1951 e na Opinião Consultiva $n^{\circ} 18$ da Corte Interamericana de Direitos Humanos. ${ }^{36}$

O conteúdo das normas jus cogens, portanto, não está limitado aos tratados internacionais, mas, ao contrário, está expandindo numa dimensão vertical, na interação entre as ordens legais internacional e nacional, invalidando todo e qualquer ato legislativo, administrativo ou medida judicial no âmbito do direito doméstico dos Estados que a desautorize.

Além disso, são normas que asseguram a absoluta proibição de violação dos direitos fundamentais da pessoa humana e que estão conectadas com os valores superiores compartilhados pela comunidade internacional. Por isso, o jus cogens emana da noção de ordem pública do direito internacional e da prevalência do jus necessarium sobre o jus voluntarium. ${ }^{37}$

36 A tese da fragmentação vertical da soberania estatal foi desenvolvida por Pogge, Thomas, "Cosmopolitanism and Sovereignty", Ethics, Chicago, núm. 1, 1992, pp. 48-75. Disponível em: https: / / www.law.upenn.edu/live/files/1914-pogge-cosmopolitanism-and-sovereigntyfull; cfr. Artigo 53 da Convenção de Viena de 1969: "É nulo um tratado que, no momento de sua conclusão, conflite com uma norma imperativa de Direito Internacional geral. Para os fins da presente Convenção, uma norma imperativa de Direito Internacional geral é uma norma aceita e reconhecida pela comunidade internacional dos Estados como um todo, como norma da qual nenhuma derrogação é permitida e que só pode ser modificada por norma ulterior de Direito Internacional geral da mesma natureza"; também, Corte Interamericana de Direitos Humanos, OC-18/03, Costa Rica, 2003. Disponível em: http://www. corteidh.or.cr/docs/opiniones/seriea_18_esp.pdf.

37 Cfr. Corte Interamericana de Direitos Humanos, caso Cantoral Benavides vs. Peru, Costa Rica, 2000. Disponível em: http://www.corteidh.or.cr/docs/casos/articulos/seriec_69_ing. pdf; caso Maritza Urrutia vs. Guatemala, Costa Rica, 2003. Disponível em: http://www.corte idh.or.cr/docs/casos/articulos/seriec_103_esp.pdf; caso Hermanos Gomes vs. Peru, Costa Rica, 2004. Disponível em: http://www.corteidh.or.cr/docs/casos/articulos/seriec_110_esp.pdf; caso Tibi vs. Equador, Costa Rica, 2004. Disponível em: http://www.corteidh.or.cr/docs/casos/articulos/seriec_114_ing.pdf; OC-8/87, Costa Rica, 1987. Disponível em: http: / /www.corteidh. or.cr/docs/opiniones/seriea_08_esp.pdf. Cfr., também, Bassiouni, M. Cherif, "International Crimes: Jus Cogens and Obligatio Erga Omnes", Law and Contemporary Problems, Durham, núm. 4, 1996, pp., 63-74. Disponível em: https://scholarship.law.duke.edu/cgi/viewcontent.cgi?article $=1016$ \& context $=1$ cp; Convenção de Viena de 1969, Artigo 64: "Se sobrevier uma nova norma imperativa de Direito Internacional geral, qualquer tratado existente que estiver 
Esta revista forma parte del acervo de la Biblioteca Jurídica Virtual del Instituto de Investigaciones Jurídicas de la UNAM

Outro argumento relevante para confirmar a tese da ineficácia dos atos de backlash nos direitos humanos é a necessidade de os Estados realizarem o controle de convencionalidade, com a compatibilização vertical das leis ou dos atos normativos do poder público com as Constituições nacionais e com os tratados internacionais de direitos humanos, conforme se extrai da Convenção de Viena sobre o Direito dos Tratados de 1969 ao estabelecer que os Estados devem tomar todas as medidas necessárias para conferir eficácia a referidos tratados internacionais, sejam ditas medidas políticas, administrativas ou legislativas, de acordo com o princípio da boa-fé e com o dever de devida diligência. ${ }^{38}$

em conflito com essa norma torna-se nulo e extingue-se". Disponível em: http: / / www.planalto.gov.br/ccivil_03/_ato2007-2010/2009/decreto/d7030.htm; Corte Internacional de Justiça, Opinião Consultiva Nicarágua vs. EUA, Haia, 1984, Disponível em: https://www. icj-cij.org/files/case-related/70/070-19860627-JUD-01-00-EN.pdf: "As normas peremptórias geram obrigações erga omnes e acarretam a responsabilidade internacional dos Estados, de modo que até mesmo um terceiro estado pode invocar a responsabilidade do outro, uma vez que a obrigação peremptória violada pertence a toda comunidade internacional, tornando-se uma obrigação multilateral. O dever de respeitar e proteger os direitos humanos em particular em face das sérias violações é uma norma peremptória de direito internacional que cria obrigações erga omnes, que geram o sentimento de que é inadmissível que um Estado exclua os direitos humanos de sua população indefinidamente”. Cfr., também, Scheuner, Ulrich, "Conflict of Treaty Provisions with a Peremptory Norm of General International Law and its Consequences”, Munich, Max-Planck-Institut für ausländisches öffentliches Recht und Völkerrecht, 1967. Disponível em: https: / /www.zaoerv.de/27_1967/27_1967_3_c_520_532.pdf; Pingrau, Antoni, "Reflections on the Effectiveness of Peremptory Norms and erga omnes Obligation before International Tribunals, Regarding the Request for an Advisory Opinion from the International Court of Justice on the Chagos Islands", Questions of International Law-QIL, Zoom, Napoli, outubro de 2018, pp. 131-146. Disponível em: http://www.qil-qdi.org/reflections-on -the-effectiveness-of-peremptory-norms-and-erga-omnes-obligations-before-international-tribunals-re garding-the-request-for-an-advisory-opinion-from-the-international-court-of-justice-on/.

38 Cfr. European Commission for Democracy Through Law (Venice Commission), "Report on the Implementation of International Human Rights Treaties in Domestic Law and the Role of Courts, Adopted by the Venice Commission at its $100^{\text {th }}$ Plenary Session”, Rome, outubro de 2014. Disponível em: https://www.venice.coe.int/webforms/documents/default. aspx?pdffile $=C D L-A D(2014) 036-e$ : "According to one of the United Nations Human Rights monitoring bodies, the basic principle governing domestic application of international human rights treaties is that «the States [when becoming party to such a treaty] are deemed to submit themselves to a legal order in which they, for the common good, assume various obligations, not in relation to other States, but towards all individuals within their jurisdiction». It has further stated that the central obligation in relation to these treaties is for States parties to give effect to the rights recognized therein. The United Nations human rights system adopts 
Esta revista forma parte del acervo de la Biblioteca Jurídica Virtual del Instituto de Investigaciones Jurídicas de la UNAM

No mesmo sentido, a Convenção Americana de Direitos Humanos de 1969 estabelece, em seu artigo 2o., o dever de devida diligência como um dever decorrente da postura dos Estados, em todas as suas esferas, em realizar e concretizar as obrigações assumidas internacionalmente, a fim de evitar danos irreparáveis às vítimas de supostas violações de direitos humanos. ${ }^{39}$

a broad and flexible approach which allows that the particularities of the legal and administrative systems of each State, as well as other relevant considerations, be taken into account". Cfr. Artigo 2o. da Convenção Americana de Direitos Humanos, 1969, "Se o exercício dos direitos e liberdades mencionados no artigo $1^{\circ}$ ainda não estiver garantido por disposições legislativas ou de outra natureza, os Estados Partes comprometem-se a adotar, de acordo com as suas normas constitucionais e com as disposições desta Convenção, as medidas legislativas ou de outra natureza que forem necessárias para tornar efetivos tais direitos e liberdades”. Cfr. Magalhães Loureiro, Claudia Regina, “A decolonialidade decorrente da jurisprudência da Corte Interamericana de Direitos Humanos. Uma análise da sentença do caso Fazenda BrasilVerde vs. Brasil sobre trabalho escravo contemporâneo”, $16^{\circ}$ Congresso Brasileiro de Direito Internacional, 2018, Foz do Iguaçu, Direito Internacional em Expansão, Belo Horizonte, vol. XIII. 2018, p. 47-65: "O dever de os Estados agir com a devida diligência decorre do artigo 2 da Convenção Americana de Direitos Humanos de 1969 como o dever que o Estado tem de prevenir e investigar possíveis situações de trabalho escravo contemporâneo, conformando-se como o marco jurídico de proteção adequado que deve ser ofertado pelo Estado, com a aplicação de políticas públicas de prevenção e de práticas eficazes. Referida ideia decorre do conceito de devida diligência como: «the diligence reasonably expected from, and ordinarily exercised by, a person who seeks to satisfy a legal requirement or discharge an obligation». Logo, os Estados devem tomar todas as medidas apropriadas para modificar ou abolir leis e regulamentos vigentes ou para modificar práticas jurídicas ou consuetudinárias que respaldem a persistência ou a tolerância ao trabalho escravo contemporâneo e modificar os padrões socioculturais imperantes na sociedade".

39 Nesse sentido, "The legal grounding of conventionality control is located principally in articles 1.1, 2, and 29 of the ACHR, and in articles 26 and 27 of the Vienna Convention on the Law of Treaties. Articles 1.1 and 2 of the ACHR outline state duties to develop practices which ensure effective observance of the rights and freedoms enshrined in the pact, thereby requiring that national laws be interpreted in such way as to comply with their obligations to respect and guarantee rights. Article 29 of the ACHR sets out authorities' duty to enable the enjoyment and exercise of rights established in the ACHR to the fullest extent possible, by effecting the most favorable interpretation of laws for this to occur. Finally, the duty of states to ensure compliance with their obligations under the ACHR are reinforced, in a subordinate manner, by the principles of good faith, effectiveness and pacta sunt servanda, as well as by a judicial ban on drawing on domestic law as a means to justify failure to comply with treaties (in accordance with articles 26 and 27 of the Vienna Convention). Collectively, these aspects provide the legal basis of conventionality control. In my view, article 25 of the ACHR additionally forms part of the legal basis of judicial conventionality control, in that this provision refers to the right to simple, prompt and effective recourse to a competent court or tribunal 
Neste sentido, interessante ressaltar o pensamento de Gonzalo Aguilar Cavallo que define o controle de convencionalidade como o ato de controle que o juiz nacional efetua para estabelecer a conformidade da norma interna com a norma internacional, bem como com os tratados internacionais perante os quais o Estado se obrigou. ${ }^{40}$

Assim, é possível afirmar que, para alcançar a justiça da decisão, o magistrado deverá compreender a lógica da dupla compatibilidade vertical material que significa que as fontes internacionais e nacionais devem dialogar entre si para solucionar a antinomia entre o tratado e a lei interna, de modo que o direito interno não justifique o descumprimento do direito internacional. ${ }^{41}$

A aplicação do controle de convencionalidade, portanto, contribui para a criação do bloco de convencionalidade, que é composto por um conjunto de normas, regras e princípios que podem ser utilizados para a realização do controle de convencionalidade. No caso do Brasil, existe um bloco de convencionalidade que contém os elementos a serem aplicados pelo intérprete da lei ao caso concreto, como, por exemplo, tratados internacionais de direito humanos, as normas constitucionais, a jurisprudência da Corte Interamericana de Direitos Humanos, as decisões da Corte Internacional de Justiça, dentre outros tribunais e órgãos. ${ }^{42}$

É nessa linha que se pode afirmar que os tratados internacionais de direitos humanos têm cláusulas de diálogo que condizem com a abertura

for «protection» against acts that violate the fundamental rights recognized by the constitution, the laws of the state concerned or by the convention itself. Accordingly, this provision constitutes an integral element of rights, in that it sets out a right to the guarantee of fundamental rights enshrined in the Convention and in national sources." Ferrer Mac-Gregor, Eduardo, "The Constitutionalization of International Law in Latin America Conventionality Control, the New Doctrine of the Inter American Court of Human Rights", ASIL, 2015. Disponível em: https: / /www.asil.org/sites/default/files/Ferrer\%20Mac-Gregor,\%20Conventionali ty\%20Control.pdf.

40 Cfr. Cavallo, Gonzalo Aguilar, "El control de convencionalidad: análisis en derecho comparado”, Revista Direito GV, São Paulo, núm. 2, 2013, pp. 721-754. Disponível em: http:// bibliotecadigital.fgv.br/ojs/index.php/revdireitogv/article/view/21451.

${ }^{41}$ Jayme, Erik, "Identité culturelle et integrtion: le droit international privé postmoderne”, Recueil des Cours, Leiden, 1995, pp. 60 e 251.

42 Sobre o bloco de convencionalidade, consultar também os seguintes precedentes da Corte Interamericana de Direitos Humanos: caso Suárez Rosero vs. Ecuador, e Barrios Altos vs. Peru, em Ferrer Mac-Gregor, Eduardo, op. cit. pp. 93-99. 
Esta revista forma parte del acervo de la Biblioteca Jurídica Virtual del Instituto de Investigaciones Jurídicas de la UNAM

dos Estados ao direito supranacional, a exemplo do que prevê a Convenção Americana sobre Direitos Humanos, em seu artigo 29, ao autorizar a intercomunicação e a retroalimentação entre o direito internacional e o interno, segundo o critério dialógico idealizado por Erik Jayme. ${ }^{43}$ Para o autor, o diálogo das fontes é um sistema que resolve os conflitos oriundos da fragmentação do direito internacional, que se intensificou com sua proliferação normativa gerando antinomias que afetaram a coerência do direito internacional. ${ }^{44}$

É nesse sentido, que o pensamento de Lauterpacht merece ser destacado no sentido de que a passagem das normas de coexistência para a cooperação e a transição de um direito internacional de base contratual para um direito de cunho objetivo, com o respeito à vontade da comunidade internacional, ensejou a necessidade de releitura do princípio do pacta sunt servanda. ${ }^{45}$

${ }^{43}$ Jayme, Erik, op. cit.

${ }^{44}$ Cfr. Ferrer Mac-Gregor, Eduardo, op. cit., p. 94. O tema em apreço é recorrente na jurisprudência da Corte Interamericana de Direitos humanos e foi abordado no parágrafo 206 da sentença do caso Cabrera Garcia e Montiel Flores vs. México que consignou que os Estados devem aplicar nacionalmente os direitos humanos previstos nos pactos internacionais, bem como a jurisprudência da Corte Interamericana de Direitos Humanos. Além disso, o Pacto de San José da Costa Rica, em seus artigos 76 e 77 também faz menção ao bloco de convencionalidade quando afirma que os Estados podem criar Protocolos Adicionais que fortaleçam a Convenção, incluindo no sistema de proteção novos direitos e liberdades. Por outro lado, $C f r$. Amaral, Alberto Jr., "O diálogo das fontes: fragmentação e coerência do direito internacional contemporâneo", Anuário Brasileiro de Direito Internacional, Belo Horizonte, vol. 2, núm. 3, 2008, pp. 11-31: Com base no diálogo das fontes, método que coexista com as soluções tradicionais para aplicar de forma simultânea, coerente e coordenada, as várias fontes do direito internacional de modo a eliminar a norma incompatível quando se verificar que a contradição que ela causa é insuperável. Cfr., também, Pauwelyn, Joost, Conflict of Norms in Public International Law, Londres, Cambridge University Press, 2003, pp. 17-23.

45 Reis, Gabriel Valente, "Comunidade internacional e monismo", Revista Eletrônica de Direito e Política do Programa de Pós-Graduação Stricto Sensu em Ciência Jurídica da UNIVALI, Itajaí, núm. 1, 2020, p. 479. Disponível em: www.univali.br/direitoepolitica. Cfr. De Man, Philip, "State Practice, Domestic Legislation and the Interpretation of Fundamental Principles of International Space Law", Working Paper, Leuven, núm. 181, 2017, p. 17. Disponível em: https://ghum.kuleuven.be/ggs/publications/working_papers/2017/181deman: "In this regard, the International Law Commission has found that (T)reaties characterized by considerations of humanity or other general community interests... presumably aim at a uniform interpretation as far as they establish minimum obligations and do not leave a scope for the exercise of discretion to States". 
Esta revista forma parte del acervo de la Biblioteca Jurídica Virtual del Instituto de Investigaciones Jurídicas de la UNAM

Assim, como asseverou Christian Tomuschat, as atividades estatais têm repercussão para além das fronteiras e a limitação da soberania absoluta tem base em fundamentos morais que devem ser preservados a fim de se assegurar um grau mínimo de civilização para a humanidade para a paz e a fruição dos direitos humanos, e, nesse contexto, Paul Guggenheim afirma que existem normas que não se referem à vontade dos Estados, uma vez que existem costumes internacionais, que obrigam os Estados. ${ }^{46}$

Nesse sentido, haveria um monismo necessário, que não propõe a sobreposição do direito interno sobre o internacional ou vice-versa, mas sim, que deve se conformar com a comunidade internacional atualmente imperante, de modo que as fontes dialoguem entre si, no sentido de consolidar a prevalência dos direitos humanos, com a vitória do jusnaturalismo sobre o voluntarismo. ${ }^{47}$

O direito costumeiro também poderá ser utilizado como um forte argumento para afirmar que a Venezuela não está exonerada do seu dever de

46 Cfr. Reis, Gabriel Valente, op. cit., pp. 480-481; Gardiner, Richard, Part II Interpretation Applying the Vienna Convention on the Law of Treaties. A the General Rule, 5 The General Rule: (1) The Treaty, its Terms, and their Ordinary Meaning, 2 ed., Oxford, Oxford International Law Library, 2015, p. 7. Disponível em: https://www.icc-cpi.int/RelatedRecords/CR2018_04585.PDF: “'Good faith' is an excellent example of a term whose 'ordinary meaning' is elusive. The dictionary reference to the phrase «good faith» takes one to a separate entry for «bona fides», via the definition (unhelpful in the present context) as «fidelity, loyalty». «Bona fides» is itself a relatively recent usage, the very much older one being the adverbial or adjectival «bona fide». That notion of acting honestly, without fraud or intent to deceive, is too general and ill-fitting to help in the context of treaty interpretation. To find the proper interpretation of the term «good faith», a fuller application of the Vienna rules to the term is necessary".

47 cfr. European Commission for Democracy Through Law, op. cit., pp. 6 e 7, a propósito da relação entre a teoria dualista e a teoria monista, importante ressaltar que: "Traditionally, two main approaches to the relationship between international and national law have been distinguished: the monist approach (monism) and the dualist approach (dualism). The two approaches are by no means mutually exclusive, as many States combine elements of monism and dualism within their legal orders. In fact, most States today belong to what could be described as a mixed type, showing the universal evolution from strict dualism that most States embraced in the past, to moderate monism, with special treatment reserved to certain sources of international law (usually international treaties or, in some cases, only international human rights treaties). In principle, common law countries tend to stick to dualism more persistently than their civil law counterparts, although this rule is not without exceptions. The transition from dualism to monism often accompanies political transition - thus, many countries of Central and Eastern Europe incorporated elements of monism into their legal orders after the fall of communism at the end of the 1980s". 
Esta revista forma parte del acervo de la Biblioteca Jurídica Virtual del Instituto de Investigaciones Jurídicas de la UNAM

cumprir e respeitar os direitos humanos, mesmo diante de sua retirada da OEA e da denúncia da Convenção Americana de Direitos Humanos, uma vez que os tratados internacionais e o direito internacional costumeiro são as duas principais fontes do direito internacional que têm força obrigatória diferenciada, enquanto os tratados obrigam os Estados parte, um costume não escrito obriga todos os Estados. ${ }^{48}$

Assim, a prática progressiva da regra prevista num tratado pode desenvolver uma regra costumeira que, pela teoria clássica, conjuga o elemento objetivo, a opinio juris dos Estados, com o elemento subjetivo, a crença na lei ou na sua necessidade e com o core right de Cassese. ${ }^{49}$

Nesse sentido, Kai Ambos explica que, de acordo com o direito consuetudinário internacional desenvolvido sobre as bases do direito de $\mathrm{Nu}$ remberg, uma conduta não escrita pode ser punida, se ela era punível segundo os princípios gerais de direito imperantes na comunidade internacional, ${ }^{50}$ o que conduz à compreensão de que um costume pode ser universal e obrigar os Estados com a sua interpretação conjunta com os

48 Tan, Yudan, “The Rome Statute as Evidence of Customary International Law”, Utrecht Journal of International and European Law, Ultrecht, núm. 2, novembro de 2018, pp. 92-110. Disponível em: https://www.utrechtjournal.org/articles/10.5334/ujiel.434/.

49 Cassese, Antonio, International Criminal Law, 2a. ed., Oxford, Oxford University Press, 2008 .

50 "No que diz respeito, em particular, às fontes do direito penal internacional, a fundamentação no direito consuetudinário de normas de direito penal internacional coloca especiais dificuldades em um duplo sentido. Desde a ótica do direito penal, o princípio nullum crimen parece excluir a existência de tipos penais não escritos, fundados no costume internacional. No entanto, conforme os artigos 15 (2), PIDCP; 11 (2), DUDH e 7 (2), CEDH, uma conduta pode ser sancionada, se ela era punível "segundo os princípios gerais do direito reconhecidos pela comunidade internacional”. Aqui, o conceito princípios de direito não dever ser entendido no sentido do artigo 38 (1) (c), ECIJ, senão no das regras de direito consuetudinário internacional desenvolvidas sobre a base do direito de Nuremberg, razão pela qual a regra aplicada deve ter, sem dúvida, o caráter de costume internacional”. Cfr. Ambos, Kai, A parte geral do direito penal internacional. Bases para uma elaboração dogmática, trad. Carlos Eduardo Adriano Japiassú e Daniel Andrés Raizman, São Paulo, Editora Revista dos Tribunais. 2008 , pp. 44-45. A carga normativa do princípio nullum crimen perdeu a sua importância com a aprovação adicional dos chamados elementos dos crimes na quinta sessão da Preparatory Commission (Prep-Commis) em Nova York e definitivamente pela Assembleia dos Estados Partes em sua primeira reunião em setembro de 2003. Embora não possuam efeito vinculante, auxiliam a Corte na atividade interpretativa, desde que compatível com o Estatuto do TPI, Cfr. Falk, Richard et al., International Law andWorld Order:A Problem-Oriented Coursebook, 2a. ed., Londres, West Academic, 1933, p. 76. 
Esta revista forma parte del acervo de la Biblioteca Jurídica Virtual del Instituto de Investigaciones Jurídicas de la UNAM

princípios gerais de direito, que podem ser utilizados para corroborar a existência ou não de um costume internacional, de modo que referida combinação poderia consolidar a existência de uma nova regra de direito internacional. ${ }^{51}$

Assim, se for o entendimento da comunidade internacional que determinadas condutas dos Estados devem estar de acordo com o direito costumeiro internacional, por refletirem o contexto do core right do direito internacional dos direitos humanos, estará formado o direito costumeiro internacional que autoriza os tribunais internacionais a responsabilizar internacionalmente os Estados pelo seu descumprimento.

51 Cfr. Ambos, Kai, op. cit., pp. 46-47. "Desde a ótica do direito penal internacional, apresenta-se o problema de que a práxis dos Estados (repetitivo facti), que deve estar acompanhada de um convencimento jurídico geral (opinio juris), dificilmente possa se fundamentar para dar origem ao direito consuetudinário internacional, frente à ampla extensão da impunidade das severas violações aos direitos humanos. Este problema pode ser atendido mediante uma maior acentuação dos princípios gerais de direito. Primeiramente, os princípios gerais de direito existentes podem ser considerados para a verificação ou falsidade das regras de direito consuetudinário internacional em formação, e em consequência, ainda não consolidadas. No caso de verificação da regra de direito consuetudinário internacional correspondente, fundamentar-se-ia, por meio de uma semelhante solução de combinação, uma nova regra de direito internacional. Com isto, se desenvolveria um princípio geral de direito — de modo absolutamente tradicional - a partir do direito nacional e com pesquisas de direito comparado - em certo modo, como «general principles of law derived (...) from national laws of legal systems of the world (...)» (art. 38.1. c, ECIJ). Além disso, segundo a opinião preponderante na atualidade, os princípios gerais de direito podem se fundamentar, também, em uma valoração de conjunto de «soft law» internacional, com um a espécie de «opinio juris without concordant state pratice». Neste sentido, argumentou o Tribunal para a antiga Yugoslávia (ICTY), quando fundou uma proibição fundamental de represálias em caso de ataques a civis em campo de batalha, essencialmente nas «demands of humanity and the dictates of public conscience, as manifested in opinio necessitatis». Tal compreensão moderna dos princípios gerais de direito conduz a uma assimilação do direito consuetudinário internacional com os princípios gerais do direito, no sentido de transcendentes princípios e normas de direito internacional (principles and rules of international law), segundo o artigo 21 (1) (b). Com isto, o direito consuetudinário internacional é parte das normas (rules); e os princípios gerais de direito contém uma dupla função: por um lado, como regras supranacionais originárias, colaborariam na formação do costume internacional ou — segundo uma compreensão moderna - de regras de direito internacional. Por outro lado, como princípios gerais de direito, em sentido tradicional, representam uma fonte autônoma. Neste sentido, embora segundo o artigo 21 (1) (c) devam aplicar-se só de forma subsidiária, assumem uma considerável importância em atenção do estado ainda rudimentar do direito penal internacional, escrito e não escrito, especialmente em sua Parte Geral”. 
No caso da opinião consultiva em apreço, conforme já foi salientado, o Estado pode se valer de sua soberania nacional e denunciar um tratado ou se retirar de uma organização internacional regional, mas tais atos restritos ao âmbito da manifestação da vontade dos Estados não estarão aptos a gerar o efeito de exonerar o Estado do cumprimento das normas de natureza jus cogens e do costume internacional consagrado, o que pode ensejar a sua responsabilização internacional perante os tribunais internacionais competentes.

\section{DAS CONSEQUÊNCIAS JURÍDICAS DA PRÁTICA DOS ATOS}

DE BACKLASH PRATICADOS PELA VENEZUELA

Conforme salientado, o artigo 78 da Convenção Americana de Direitos Humanos de 1969 estabelece a possibilidade de um Estado denunciar um tratado ${ }^{52}$ caso em que, as obrigações dos Estados, antes do ato unilateral de seu afastamento, persistem e geram responsabilização à data da extinção da obrigatoriedade da denúncia. Além disso, a denúncia da Convenção não atinge os efeitos de outro tratado internacional regional.

Ainda é relevante destacar que, de acordo com a Convenção Americana, a denúncia, remoção, restrição ou regulação de direitos deve estar revestida de legalidade de acordo com o interesse público, de modo que a falta de um ato legal pode fazer com que a denúncia seja negada se for revestida de manifesta violação das regras fundamentais de direito doméstico. ${ }^{53}$

52 Cfr. Artigo 78 da Convenção Americana de Direitos Humanos de 1969: "1. Os Estados-Partes poderão denunciar esta Convenção depois de expirado um prazo de cinco anos, a partir da data de entrada em vigor da mesma e mediante aviso prévio de um ano, notificando o Secretário-Geral da Organização, o qual deve informar as outras Partes. 2. Tal denúncia não terá o efeito de desligar o Estado-Parte interessado das obrigações contidas nesta Convenção, no que diz respeito a qualquer ato que, podendo constituir violação dessas obrigações, houver sido cometido por ele anteriormente à data na qual a denúncia produzir efeito". Disponível em: https: / / www.cidh.oas.org/basicos/portugues/c.convencao_americana.htm.

53 Cfr. Perez, Edward, "Problems and Perspectives on the Denunciation of American Convention on Human Rights", s/f. Disponível em: https://www.academia.edu/9682068/ Problems_and_Perspectives_on_the_Denunciation_of_American_Convention_on_Human_Rights_ LL.M._Thesis_. 
Logo, se a denúncia for realizada sem a observância do processo constitucional doméstico, será manifestamente inconstitucional, por violar previsões de direito constitucional fundamentais e, se for realizada sem o compliance com a Convenção Americana de Direitos Humanos, será inconvencional e o ato unilateral do Estado não surtirá o efeito esperado. ${ }^{54}$

Além disso, a denúncia prevista no artigo 78 da Convenção Americana deve ser interpretada de acordo com o artigo 31.1 da Convenção de Viena sobre Direito dos Tratados de 1969, com o artigo 29 da Convenção Americana de Direitos Humanos, de acordo com a Opinião Consultiva $\mathrm{n}^{\circ} 2$ sobre os Efeitos das Reservas para a entrada em vigor da Convenção Americana de Direitos Humanos e de acordo com o artigo 62 (3) da CADH que, em conjunto, indicam que a Corte tem competência para determinar a validade da denúncia, com ou seja, no seu contexto, objeto e objetivo, vedando a interpretação no sentido de suprimir ou restringir o exercício dos direitos e liberdades reconhecidos na Convenção e de acordo com a prática de outros instrumentos de direito internacional de direitos humanos quando interpretam outros tratados de proteção aos direitos humanos, conferindo-se à Corte a competência para se manifestar sobre a validade da denúncia. ${ }^{55}$

Dessa forma, o artigo 78 da CADH deve ser interpretado de maneira a garantir os direitos materiais previstos na Convenção, buscando o cumprimento de seus standards, pois esta tem como objeto e propósito a proteção dos direitos individuais contra atos que os tornem inefetivos ou ilusórios. Logo, a denúncia à Convenção só pode ser válida se o Estado que a pretende, cumprir com todas as suas obrigações perante os indivíduos sob sua jurisdição para evitar que a denúncia represente uma transgressão à Convenção. ${ }^{56}$

54 Cfr. Pérez, Antonio F, "Democracy Clauses in the Americas: The Challenge of Venezuela's withdrawal from the OAS”, American University International Law Review, Washington D C, 2017. Disponível em: https: / /ssrn.com/abstract $=3103026$; $c$ fr. Parágrafo $2^{\circ}$ do preâmbulo e artigo 30 da CADH; artigo 3 (d) da Carta da OEA; cfr. artigo 46; e Parte V, Seção 2 da Convenção de Viena sobre Direito dos Tratados, 1969. Disponível em: http: / / www.planalto.gov.br / ccivil_03/_ato2007-2010/2009/decreto/d7030.htm.

55 Cfr. Artigo 31.1 da Convenção de Viena sobre Direito dos Tratados, 1969. Disponível em: http://www.planalto.gov.br/ccivil_03/_ato2007-2010/2009/decreto/d7030.htm; artigo 29 da Convenção Americana de Direitos Humanos e OC-2/82 da Corte Interamericana de Direitos Humanos. Disponível em: http: / /www.corteidh.or.cr/docs/opiniones/seriea_02_esp.pdf.

56 Cfr. Corte Interamericana de Direitos Humanos, caso Ivcher Bronstein vs. Peru, Costa Rica, 1999. Disponível em: https://www.cnj.jus.br/wp-content/uploads/2016/04/506ad88087f45ce $5 d 2413 e f c 7893958$ e.pdf. 
Sobre a retirada da Organização, o artigo 143 da Carta da OEA estabelece que a Carta continuará válida após dois anos do recebimento da denúncia do Estado. ${ }^{57}$ Logo, o Estado deixará de pertencer à OEA depois de cumprir com a totalidade das obrigações oriundas da presente Carta, caso contrário, a retirada não se concretizará. ${ }^{58}$

Além dos aspectos legais envolvendo a retirada da organização e previstos na Carta da OEA, ainda é preciso acrescentar que referida retirada é difícil de ser concretizada em uma sociedade globalizada, em que os Estados atuam em cooperação internacional e, além disso, na qual os atos praticados por um Estado ultrapassam as fronteiras porosas e frágeis, gerando efeitos no território de outros Estados, a exemplo da migração.

A tese do direito transnacional contribui para a compreensão da ideia acima exposada ao defender a consideração da soberania estatal além de sua acepção tradicional e ao propor a reconsideração da compreensão tradicional do princípio da territorialidade, que não se aplica perfeitamente ao contexto transnacional, e assinala que a jurisdição de um Estado seja exercida extraterritorialmente para ensejar a responsabilização internacional do indivíduo que propagar ofensas aos direitos humanos. ${ }^{59}$

57 A retirada do consentimento da jurisdição da Corte Interamericana de Direitos Humanos é diferente de denúncia. Esta representa um ato unilateral do Estado para colocar fim às obrigações assumidas com o tratado, enquanto aquela, se refere à retirada do Estado de suas obrigações procedimentais. A Convenção Americana de Direitos Humanos não prevê a retirada do consentimento dado por um Estado para se submeter à jurisdição obrigatória da Corte Interamericana de Direitos Humanos. Assim, a retirada só poderá ocorrer se o Estado denunciar a Convenção Americana. De acordo com o artigo 56 (2) da Convenção de Viena sobre Direitos dos Tratados de 1969, mesmo que um Estado se retire unilateralmente da jurisdição da Corte IDH, tal ato só surtiria efeito um ano após a manifestação do ato. Artigo 143 da Carta da OEA. Esta Carta vigorará indefinidamente, mas poderá ser denunciada por qualquer dos Estados membros, mediante uma notificação escrita à Secretaria-Geral, a qual comunicará em cada caso a todos os outros Estados as notificações de denúncia que receber. Transcorridos dois anos a partir da data em que a Secretaria-Geral receber uma notificação de denúncia, a presente Carta cessará seus efeitos em relação ao dito Estado denunciante e este ficará desligado da Organização, depois de ter cumprido as obrigações oriundas do presente Carta.

58 Pérez, Antonio F., op. cit.

59 Cfr. Jessup, Philip C., Direito transnacional, Brasil-Portugal, Editora Fundo de Cultura, 1965, p.12. "Todavia, eu usarei, em lugar de direito internacional, a expressão direito transnacional para incluir todas as normas que regulam atos ou fatos que transcendem fronteiras nacionais. Tanto o direito público quanto o privado estão compreendidos, como estão 
Entretanto, no âmbito transnacional, outros critérios devem ser adotados para o exercício da jurisdição por parte de um Estado e, mesmo que se tratasse apenas de direito internacional, já seria possível afirmar que o Estado não é mais absoluto e pleno no exercício de sua jurisdição, uma vez que existe o interesse internacional em prol dos direitos humanos, o que faz com que os Estados sejam persuadidos a aceitar a jurisdição de uma justiça internacional, podendo-se falar em princípio da territorialidade objetiva. ${ }^{60}$

O direito transnacional, portanto, distribui a jurisdição de maneira mais proveitosa para as necessidades e conveniências de todos os membros da comunidade internacional, ao envolver instituições de diferentes países, bem como as instituições pertencentes ao sistema jurídico internacional e aos órgãos internacionais de proteção aos direitos humanos.

Além disso, o Direito Cosmopolita, também corrobora o entendimento de que a atuação de um Estado se dá de forma cooperada e que seus atos devem ser considerados e avaliados de acordo com os interesses da humanidade e independentemente de seus interesses pessoais. O direito cosmopolita se destina a proteger a emergência da sociedade civil global e tem uma acepção que é compatível com uma espécie de federação global dos Estados, ${ }^{61}$ que pressupõe a dicotomia entre a visão estatocêntrica e a visão cosmopolita, sendo que a primeira enfatiza a nação, enquanto que a segunda, tem o foco no direito global. ${ }^{62}$

outras normas que não se enquadram inteiramente nessas categorias clássicas”. A propósito do princípio da territorialidade, consequência da soberania estatal, oportuna a citação do caso Lótus, julgado pela Corte Permanente de Justiça Internacional que assentou a tese de que um Estado não pode exceder os limites traçados pelo direito internacional para o exercício da jurisdição e que o direito de exercer a sua jurisdição está limitado pela soberania. Nesse sentido, o Estado faz a lei dentro de seu próprio território, onde exerce sua soberania sobre seus cidadãos para produzir efeitos no seu próprio território.

${ }^{60}$ Cfr. Jessup, Philip C., op. cit., p. 49.

${ }^{61}$ Cfr. Habermas, Jürgen, Sobre a Constituição da Europa, trad. Denilson L. Werle, Luiz Repa e Rúrion Melo, São Paulo, Unesp, 2012.

62 Cfr., Beck, Ulrich, "World at Risk: The New Task of Critical Theory", Development and Society, núm. 1, 2003, pp. 1-21. "The cosmopolitanization of reality is not the result of a cunning conspiracy on the part of «global capitalists» or an «American play for world domination». The nation-state is increasingly besieged and permeated by a planetary network of interdependency, by ecological, economic and terrorist risks, which connect the separate worlds of developed and underdeveloped countries. To the extent that this historical situation is reflected in a global public sphere, a new historical reality rises, a cosmopolitan outlook in which people view themselves simultaneously as part of a threatened world and as part 
Esta revista forma parte del acervo de la Biblioteca Jurídica Virtual del Instituto de Investigaciones Jurídicas de la UNAM

Nesse sentido, para Thomas Pogge, o cosmopolitismo legal está fundado numa ordem global em que todos são cidadãos de uma república universal, com direitos e deveres equivalentes. Por sua vez, o cosmopolitismo moral implica necessariamente o respeito mútuo, na medida em que todos têm uma estatura global com uma unidade moral com princípios fundamentais de justiça. ${ }^{63}$

O direito cosmopolita, portanto, se refere a regras que reconhecem standards legais para todos igualmente, sem abolir o aspecto nacional e surge do lado de fora das fronteiras dos Estados. Assim, o contrato social cosmopolita consolida seus ideais nas obrigações de cidadania, para a cooperação social, possibilitando que as pessoas exerçam seus direitos fundamentais em qualquer lugar do mundo. ${ }^{64}$

of their local situations and histories. The exposure to different risks and religious cultures gives them a particular understanding of a world in which violent division and unprecedented intermingling coexist, and anger and opportunity vie”.

63 Cfr. Pogge, Thomas, op. cit., pp. 48-75. O cosmopolitismo nem sempre propõe o fim da soberania estatal, mas, ao contrário, propõe uma mudança de paradigma. Tradicionalmente, a soberania de um Estado é exercida sobre um determinado território e sobre pessoas que devem lealdade a este Estado, mas a concentração da soberania num único nível e centrada nos interesses fundamentais dos estados não mais se sustenta. Ao contrário do que se possa imaginar, Pogge não defende a criação de um Estado Universal, mas sim uma visão verticalmente descentralizada da soberania, com diversas unidades políticas pertencentes a um federalismo, propondo a dispersão vertical da soberania estatal, com a existência de unidades políticas organizadas que fiscalizariam o exercício da soberania estatal, evitando abuso, opressão e possibilitando a abertura do Estado ao Direito Cosmopolita. Assim, unidades políticas descentralizadas e coordenadas podem representar a diversidade social e defender melhor os interesses das comunidades globais, pois, quando um Estado aplica o sentido clássico de soberania estatal, de acordo com Pogge, está se negando a incluir o outro, os seres humanos, no processo de tomada de decisão, o que reflete uma organização política e estatal autoritária, que centraliza as decisões numa única autoridade política que não aceita ser fiscalizada por outra unidade política e que, por isso, nega a descentralização vertical da soberania. A dispersão vertical da soberania seria benéfica para a promoção da paz e da segurança; para a redução da opressão praticada pelos governos sobre seus cidadãos; para a promoção de uma justiça econômica global; para o uso dos recursos naturais materiais para suportar o desenvolvimento das áreas mais pobres; para o meio ambiente e para o fomento da participação política.

${ }^{6}$ Cfr. Eleftheriadis, Pavlos, “Cosmopolitam law”, European Law Journal, núm. 2, 2003, pp. 241-263. Disponível em: https://www.researchgate.net/publication/227912556_Cosmopoli tan_Law. "The word «cosmopolitan», which derives from the Greek word kosmopolitês (citizen of the world), has been used to describe a wide variety of important views in moral and sociopolitical philosophy. The nebulous core shared by all cosmopolitan views is the idea that all human beings, regardless of their political affiliation, are (or can and should be) citizens in a 
Esta revista forma parte del acervo de la Biblioteca Jurídica Virtual del Instituto de Investigaciones Jurídicas de la UNAM

Logo, a retirada de um Estado da OEA não se consolidará diante da tese do direito transnacional e do direito cosmopolita, pelos fundamentos acima explicitados.

\section{CONSIDERAÇÕES FINAIS}

A pesquisa ora realizada possibilitou concluir que embora um Estado denuncie a $\mathrm{CADH}$, não estará exonerado do dever de respeitar os direitos humanos dos indivíduos sob sua jurisdição, em sentido amplo, devido ao contexto das normas jus cogens e ao costume internacional que considera os direitos humanos como mínimo necessário para a manutenção da dignidade humana.

Além disso, a denúncia não surtirá efeitos se a decisão do Estado em exercitar referido direito não decorrer da expressão da democracia e do respeito aos documentos interamericanos mencionados na manifestação. Assim, se a decisão de denunciar a CADH não for a verdadeira expressão da vontade de um povo, esta não operará os efeitos esperados pelo Estado denunciante.

Se o Estado que pretende se retirar da organização internacional não cumprir com as obrigações decorrentes da Carta da OEA, sua retirada não se concretizará e os demais Estados membros da OEA têm o dever de devida diligência em exigir que os Estados respeitem o paradigma interamericano para proteção e efetivação dos direitos humanos no sistema

single community. Different versions of cosmopolitanism envision this community in different ways, some focusing on political institutions, others on moral norms or relationships, and still others focusing on shared markets or forms of cultural expression. In most versions of cosmopolitanism, the universal community of world citizen's functions as a positive ideal to be cultivated, but a few versions exist in which it serves primarily as a ground for denying the existence of special obligations to local forms of political organizations. Versions of cosmopolitanism also vary depending on the notion of citizenship they employ, including whether they use the notion of «world citizenship» literally or metaphorically. The philosophical interest in cosmopolitanism lies in its challenge to commonly recognized attachments to fellowcitizens, the local state, parochially shared cultures, and the like”. Cfr. também, Rosas, Allan, "State Sovereignty and Human Rights: towards a Global Constitutional Project", Political Studies, Thousand Oaks, março de 1995, pp. 61-78. Disponível em: https://journals.sagepub. $\mathrm{com} / \mathrm{doi} / 10.1111 / \mathrm{j} .1467-9248.1995 . t b 01736 . x$. 
Esta revista forma parte del acervo de la Biblioteca Jurídica Virtual del Instituto de Investigaciones Jurídicas de la UNAM

interamericano, em decorrência da tese da transnacionalidade e do direito cosmopolita.

Os atos de backlash praticados pela Venezuela não surtem o efeito esperado, uma vez que refletem a prática de simulação por aquele país com o intuito de ofuscar a ofensa e o desrespeito aos direitos humanos em seu território.

Assim, os demais países, em sistema de cooperação internacional, de acordo com o direito transnacional e cosmopolita podem exigir que outros Estados respeitem os direitos humanos e os indivíduos podem se utilizar dos mecanismos de proteção aos direitos humanos existentes nos sistemas universal e regional, como os comitês dos tratados internacionais, bem como o sistema de peticionamento individual do sistema interamericano para concretizar os direitos humanos.

\section{REFERÊNCIAS BIBLIOGRÁFICAS}

Alter, Karen J. e Zürn, Michael, "Backlash Politics: Introduction to a Symposium on Backlash Politics in Comparison, Forthcoming in the British Journal of Politics and International Relations, as Part of a Special Issue on Backlash Politics in Comparison”, iCourts Working Paper Series, Copenhagen, núm. 174, novembro de 2019. Disponível em: https: / / papers.ssrn. $\mathrm{com} /$ sol3 / papers.cfm?abstract_id $=3481735$.

AmARAL, Alberto Jr., "O diálogo das fontes: fragmentação e coerência do direito internacional contemporâneo", Anuário Brasileiro de Direito Internacional, Belo Horizonte, vol. 2, núm. 3, 2008.

Ambos, Kai, A parte geral do direito penal internacional. Bases para uma elaboração dogmática, trad. Carlos Eduardo Adriano Japiassú e Daniel Andrés Raizman, São Paulo, Editora Revista dos Tribunais. 2008.

BAHAR, Dany et al., "Integrating Venezuelans into the Colombian Labor Market. Mitigating Costs and Maximizing Benefitis", Global Economy and Development at Brookings, 2018. Disponível em: https://www.brookings. edu/wp-content/uploads/2018/12/Venezuelan-Migrants_English.pdf.

Bassiouni, M. Cherif, "International Crimes: Jus Cogens and Obligatio Erga Omnes", Law and Contemporary Problems, Durham, núm. 4, 1996. 
Disponível em: https://scholarship.law.duke.edu/cgi/viewcontent.cgi?arti cle $=1016$ \&ontext $=1 p$

BECK, Ulrich, "World at Risk: The New Task of Critical Theory", Development and Society, núm. 1, 2003.

BurCHARDT, Dana, "Backlash against the Court of Justice of the EU? The Recent Jurisprudence of the German Constitutional Court on EU Fundamental Rights as a Standard", Review German Law Journal, Cambridge, núm. 21, março de 2020. Disponível em: https: / / doi.org/10.1017/ glj.2020.16.

CAnÇADO TRindade, Antonio Augusto, "Jus Cogens: The Determination and the Gradual Expansion of its Material Content in contemporary International Case-Law", s/f. Disponível em: https: / / www.oas.org/dil/esp/3\%20 -\%20cancado.LR.CV.3-30.pdf.

Cançado Trindade, Antonio Augusto, O direito internacional em um mundo em transformação, Rio de Janeiro, Renovar, 2002.

CANÇADO TRINDADE, Antonio Augusto, Os tribunais internacionais contemporâneos, Brasília, FUNAG, 2013.

CASSESE, Antonio, International Criminal Law, 2a. ed., Oxford, Oxford University Press, 2008.

Cavallo, Gonzalo Aguilar, "El control de convencionalidad: análisis en derecho comparado", Revista Direito GV, São Paulo, núm. 2, 2013. Disponível em: http: / / bibliotecadigital.fgv.br/ojs/index.php/revdireitogv/article/ view / 2145 .

COMisSÃo InTERAmERICANA DE Direitos Humanos, "Relatório da Venezuela de 2017", Washington DC, 2017. Disponível em: http:/ / www.oas. org/es/cidh/informes/pdfs/Venezuela2018-es.pdf.

CONCEPCION, Natasha, "The Legal Implications of Trinidad \& Tobago's Withdrawal from the American Convention on Human Rights", American University International Law Review, Washington DC, núm. 3, 2001. Disponível em: https://digitalcommons.wcl.american.edu/cgi/viewcontent. cgi? article $=1242$ \&context $=$ auilr.

DE MAN, Philip, "State Practice, Domestic Legislation and the Interpretation of Fundamental Principles of International Space Law", Working Paper, Leuven, núm. 181, 2017. Disponível em: https: / /ghum.kuleuven. be/ggs/publications/working_papers/2017/181deman.

Dooy, Shannon et al., "Venezuelan Migration and the Border Healthy Crisis in Colombia and Brazil", Journal on Migration and Human Security, Bal- 
timore, núm. 3, 2019. Disponível em: https: / /journals.sagepub.com/doi/ pdf/10.1177/2331502419860138.

EHRHARDT, Matthias, "Why Parties Politicize International Institutions: On Globalization Backlash and Authority Contestation", Review International Political Economy, Londres, núm. 6, 2014. Disponível em: https: / / www. tandfonline.com / doi / full/10.1080/09692290.2013.839463.

Eleftheriadis, Pavlos, "Cosmopolitam law", European Law Journal, núm. 2, 2003. Disponível em: https: //www.researchgate.net/publication /227912556_Cosmopolitan_Law.

European Commission for Democracy Through LaW (Venice Commission), "Report on the Implementation of International Human Rights Treaties in Domestic Law and the Role of Courts, Adopted by the Venice Commission at its $100^{\text {th }}$ Plenary Session”, Rome, outubro de 2014. Disponível em: https: / / www.venice.coe.int/webforms/documents / default.asp $x$ ?pdffile $=C D L-A D(2014) 036-e$.

FALK, Richard et al., International Law and World Order: A Problem-Oriented Coursebook, 2a. ed., Londres, West Academic, 1933.

FERRER MAC-GREGOR, Eduardo, "The Constitutionalization of International Law in Latin America Conventionality Control, the New Doctrine of the Inter American Court of Human Rights", ASIL, 2015. Disponível em: https: / / www. asil.org/sites / default / files / Ferrer\%20Mac-Gregor, \%20Conventionality\%20Control.pdf.

Gardiner, Richard, Part II Interpretation Applying the Vienna Convention on the Law of Treaties. A the General Rule, 5 The General Rule: (1) The Treaty, its Terms, and their Ordinary Meaning, 2 ed., Oxford, Oxford International Law Library, 2015. Disponível em: https: //Www.icc-cpi.int/RelatedRecords / CR2 018_04585.PDF.

Habermas, Jürgen, Sobre a Constituição da Europa, trad. Denilson L. Werle, Luiz Repa e Rúrion Melo, São Paulo, Unesp, 2012.

Human Rights Watch, "The Venezuelan Exodus, the Need for International Protection and the Region's Response", 2018. Disponível em: https: / / www.hrw.org/pt/report/2018/09/03/322156.

InTERnational CRIminal COURT, "Report on Preliminar Examination Activities", Haia, 2018. Disponível em: https: //www.icc-cpi.int/itemsDo cuments / 181205-rep-otp-PE-ENG.pdf.

JAYME, Erik, "Identité culturelle et integrtion: le droit international privé postmoderne”, Recueil des Cours, Leiden, 1995. 
Jessup, Philip C., Direito transnacional, Brasil-Portugal, Editora Fundo de Cultura, 1965.

KLeingeld, Pauline et. al., "Cosmopolitanism", em Zalta, Edward N. (ed.), The Stanford Encyclopedia of Philosophy, Palo Alto, 2014. Disponível em: https: / / plato.stanford.edu/archives/fall2014/entries/cosmopolitanism/.

Magalhães Loureiro, Claudia Regina, "A decolonialidade decorrente da jurisprudência da Corte Interamericana de Direitos Humanos. Uma análise da sentença do caso Fazenda Brasil Verde vs. Brasil sobre trabalho escravo contemporâneo", $16^{\circ}$ Congresso Brasileiro de Direito Internacional, 2018, Foz do Iguaçu, Direito Internacional em Expansão, Belo Horizonte, vol. XIII. 2018.

Magalhães Loureiro, Claudia Regina, Refugiados e apátridas no direito internacional, Belo Horizonte, Arraes, 2018.

MARQUES, Claudia Lima (coord.), O diálogo das fontes como método da nova teoria geral do direito: um tributo a Erik Jayme, São Paulo, Revista dos Tribunais, 2012.

MENEZES, Wagner, Tribunais internacionais: jurisdição e competência, São Paulo, Saraiva, 2013.

Pauwelyn, Joost, Conflict of Norms in Public International Law, Londres, Cambridge University Press, 2003.

PÉREZ, Antonio F., "Democracy Clauses in the Americas: The Challenge of Venezuela's withdrawal from the OAS”, American University International Law Review, Washington D C, 2017. Disponível em: https://ssrn.com/abs tract $=3103026$.

Perez, Edward, "Problems and Perspectives on the Denunciation of American Convention on Human Rights", s/f. Disponível em: https://www. academia.edu/9682068/Problems_and_Perspectives_on_the_Denunciation_ of_American_Convention_on_Human_Rights_LL.M._Thesis_.

PeTsChe, Markus, "Jus Cogens as a Vision of the International Legal Order", Penn State International Law Review, núm. 2, 2010. Disponível em: http: / / elibrary. law.psu.edu/psilr/vol29/iss2/2.

PINGRAu, Antoni, "Reflections on the Effectiveness of Peremptory Norms and erga omnes Obligation before International Tribunals, Regarding the Request for an Advisory Opinion from the International Court of Justice on the Chagos Islands", Questions of International Law-QIL, Zoom, Napoli, outubro de 2018. Disponível em: http://www.qil-qdi.org/reflections-onthe-effectiveness-of-peremptory-norms-and-erga-omnes-obligations-before-in- 
Esta revista forma parte del acervo de la Biblioteca Jurídica Virtual del Instituto de Investigaciones Jurídicas de la UNAM

ternational-tribunals-regarding-the-request-for-an-advisory-opinion-from-theinternational-court-of-justice-on /.

PogGe, Thomas, "Cosmopolitanism and Sovereignty", Ethics, Chicago, núm. 1, 1992. Disponível em: https: / / www.law.upenn.edu/live/files / 1914-pogge -cosmopolitanism-and-sovereignty-full.

RAmSEY, Geoff e SANCHEZ-GRAZOLI, Gimena, "Responding to an Exodus, Venezuela's Migration and Refugees Crisis as Seen from the Colombian and Brazilian Borders", WOLA, Advocacy for Human Rights in the Americas, Research Report, jul. de 2018. Disponível em: https: / / www.wola.org/wpcontent / uploads /2018/07/Final-VZ-Migration-Report-Final.pdf.

REIS, Gabriel Valente, "Comunidade internacional e monismo", Revista Eletrônica de Direito e Política do Programa de Pós-Graduação Stricto Sensu em Ciência Jurídica da UNIVALI, Itajaí, núm. 1, 2020. Disponível em: www.uni vali.br/direitoepolitica.

RosAs, Allan, "State Sovereignty and Human Rights: towards a Global Constitutional Project", Political Studies, Thousand Oaks, março de 1995. Disponível em: https://journals.sagepub.com/doi/10.1111/j.1467-9248.1995. tb01736.x.

Saramago, José, Ensaio sobre a lucidez, São Paulo, Companhia das Letras, 2004.

SCHEUNER, Ulrich, "Conflict of Treaty Provisions with a Peremptory Norm of General International Law and its Consequences", Munich, Max-PlanckInstitut für ausländisches öffentliches Recht und Völkerrecht, 1967. Disponível em: https: / / www.zaoerv.de/27_1967/27_1967_3_c_520_532.pdf.

Soley, Ximena e STEININGER, Silvia, "Parting Ways or Lashing back? Withdrawals, Backlash and the Inter-American Court of Human Rights", International Journal of Law in Context, Cambridge, maio de 2018. Disponível em: https: / / doi.org/10.1017/S1744552318000058.

TAN, Yudan, "The Rome Statute as Evidence of Customary International Law", Utrecht Journal of International and European Law, Ultrecht, núm. 2, novembro de 2018. Disponível em: https: / / www.utrechtjournal.org / arti cles / 10.5334/ujiel.434/.

United Nations High COMmissioner for Human Rights, "Venezuela Situation. Responding to the Needs of People Displaced from Venezuela, Supplementary Appeal", 2018. Disponível em: https: / / www.unhcr.org/ partners/donors / 5 ab8e1 a17/unhcr-2018-venezuela-situation-supplementaryappeal-january-december-2018.html. 